\title{
Clinical Profile on the PTSD Checklist for DSM-5 (PCL-5) of Veterans versus Patients Injured in Motor Vehicle Accidents
}

\author{
Zack Z. Cernovsky, Milad Fattahi, and David M. Diamond
}

\section{ABSTRACT}

Background: The 20 items of PTSD Checklist for DSM-5 (PCL-5) can be rank ordered from highest to the lowest, based on item mean scores in a particular clinical group. Thus, they can provide an overview of the relative importance of each of the symptoms represented by these 20 items, i.e., a clinical profile for the particular type of patients. This study compared such ranking of PCL-5 items by US veterans with those of patients injured in high impact motor vehicle accidents (MVAs).

Method: De-identified PCL-5 data were available for 80 post-MVA patients (mean age 38.9 years, $\mathrm{SD}=12.8$ ) and for 468 US veterans (mean age 55.4 years, $\mathrm{SD}=13.8$ ). The US veterans' data are those published by Bovin et al. in 2016.

Results and Discussion: The overall rank order of PCL-5 items was significantly similar in the two groups (Spearman's rho=.83), perhaps due to certain similarities of the two groups (potential threat to life or of severe physical injury). Both groups rated the Item 20 (sleep difficulties) as the most prominent, and they rated Item 16 (taking too many risks) and then Item 8 (trouble remembering details of the stressful event) as least prominent.

The largest clinically interesting difference in the item rank was on Item 12 (loss of interest in previously enjoyed activities) which was more prominent in the MVA patients, presumably due to their persistent postaccident pain (all but one MVA patient reported pain, and in $82.5 \%$ the pain was rated as more than mild).

Conclusions: In both groups, the ratings of sleep difficulties were the most prominent and ratings of taking excessive risks and of not remembering details of stressful evens were least prominent. The overall rank order of the 20 items was significantly similar in the two groups.

Keywords: PTSD, PCL-5, sleep disorder, veterans, car accidents.

Published Online: June 21, 2021

ISSN: $2736-5476$

DOI: $10.24018 /$ ejclinicmed.2021.2.3.54

\section{Z. Z. Cernovsky*}

Department of Psychiatry, Western

University, Ontario, Canada.

(e-mail: zcernovsuwo.ca)

M. Fattahi

(M. Psy. student) Adler Graduate Professional School, Toronto, Ontario, Canada.

D. M. Diamond

Department of Psychology, University of

South Florida, USA.

(e-mail: ddiamond@usf.edu)

*Corresponding Author

\section{INTRODUCTION}

The PTSD Checklist for DSM-5 (PCL-5) [1], [2] is a psychological questionnaire designed to measure posttraumatic stress disorder (PTSD) symptoms along with the diagnostic criteria of DSM-5 for PTSD. Psychometric properties of the PCL-5 on US veterans have been found satisfactory in a study by Bovin et al. [3]

A recent study [4] validated the PCL-5 also on patients injured in motor vehicle accidents (MVAs): the patients scored significantly higher on all 20 items of the PCL-5 than a group of controls. The PCL-5 total scores and scores on all 4 clusters (subscales) were also significantly higher in the post-MVA group of patients than in the controls.

Each of the 20 items of PCL-5 describes a different aspect or symptom of PTSD. The question arises whether or not different clinical groups with PTSD may systematically differ in their clinical profile as formed by the most frequently endorsed and the least frequently endorsed of the 20 PTSD symptoms.

The present study compares the most and the least frequently endorsed PCL-5 items by US veterans with those of persons recovering from their motor vehicle accidents (MVAs).

\section{METHOD}

Each PCL-5 item is scored via scale from $0=$ not at all, $1=a$ little bit, $2=$ moderately, $3=$ quite $a$ bit, and $4=$ extremely. This study used the average scores reported for each of the 20 items in the study on MVA-patients [4] and in Bovin et al.'s study on veterans.[3] We compared the rank order of the most 
frequently endorsed PCL-5 items by the US Veterans with the rank order of these items by post-MVA patients.

The overall similarity of the rank order was assessed via Spearman correlation coefficient.

\section{A. Patients Injured in MVAs}

De-identified data sets were available on 80 persons (34 men and 46 women) injured in high impact MVAs. These are the same patients as in the recently published validation study of PCL-5 [4]. Their age ranged from 15 to 65 years, with the mean at 38.9 years $(S D=12.8)$. The time elapsed since the patient's MVA ranged from 8 to 194 weeks, with the average at 49.7 weeks $(\mathrm{SD}=36.3)$, i.e., about a year. They all still experienced active post-accident symptoms that required therapy. These patients still experienced considerable pain (mean rating of $6.2, \mathrm{SD}=1.7$, on the "average pain" item of the Brief Pain Inventory [5]) and post-accident insomnia (mean score of 23.1, SD=4.8, on Morin's Insomnia Severity Index [6]). All patients in this sample could be classified as experiencing some degree of the post-concussion syndrome (scores ranging from 28 to 60 on the Rivermead scale [7], [8], with mean=45.5, $\mathrm{SD}=8.5$ ). Their average score was 19.9 $(\mathrm{SD}=12.9)$ on the Subjective Neuropsychological Symptoms Scale (SNPSS) [9].

Their scores on PCL-5 ranged from 16 to 80 points with the mean of $55.4(\mathrm{SD}=13.8)$.

\section{B. US Veterans}

In our data analyses, we used the mean scores of 468 US veterans on the 20 PCL- 5 items as published in a study by Bovin et al. [3] The veterans in Bovin et al.'s study was recruited through a Veterans Affairs Medical Center. Their mean age was 52.1 years $(\mathrm{SD}=11.5)$. Only $35 \%$ were exposed to combat, but all except $27.4 \%$ of them were deployed in various military conflicts. Diagnostic conditions included the major depressive syndrome (34.9\%), panic syndrome $(49.5 \%)$, generalized anxiety disorder $(27.6 \%)$, somatoform disorder $(24.6 \%)$, and alcohol abuse $(41.1 \%)$.

Their PCL-5 scores ranged from 0 to 80 with the mean of $37.0(\mathrm{SD}=21.2)$ which is lower than in our sample of patients injured in high impact MVAs. Some other samples of veterans, however, could obviously have much higher mean PCL-5 scores than our MVA patients: the present study does not compare the mean scores of the two groups, only their relative ranks of the 20 PCL-5 items.

The veterans sample consisted of only $12 \%$ women $(\mathrm{N}=56)$. At this time, unfortunately, we do not have the gender specific data on the individual PCL-5 items to evaluate if some related differences are present.

\section{RESULtS}

The purpose of this study was to evaluate which symptoms represented by the 20 PCL-5 items were most frequently endorsed by post-MVA patients and which ones by US veterans, and also, which items were endorsed the least frequently.

The average scores on each of the 20 PCL-5 items were rank-ordered from the highest to lowest. The procedure was carried out separately for the sample of post-MVA patients and for the sample of US veterans. In that manner, the relative importance of each PCL-5 item was established for these two clinical groups. The most and the least endorsed symptoms denoted by these items can be considered as forming the clinical profile of each group.

\section{A. The Highest and the Lowest Relative Frequencies of the Endorsed Items}

The relative rank orders of the symptoms are listed in Table I. It must be noted that the ranks of some items were tied: some items were endorsed with the same frequency. The rank for such tied items was averaged. For example, the same mean score of the MVA patients was found on Item 12 and on Item 17: their ranks would be 2 and 3, thus, the average rank was calculated as 2.5. Similarly, the same mean scores of MVA patients were found on Items 1, 13, and 18: their shared ranks would be 8,9 , and 10: thus, their average rank was calculated as 9 .

TABLE 1: ITEM RANK ON PCL-5 IN POST-MVA PATIENTS VERSUS VETERANS

\begin{tabular}{|c|c|c|}
\hline \multirow[b]{2}{*}{ PCL-5 Items: } & \multicolumn{2}{|c|}{$\begin{array}{l}\text { Rank of the PCL-5 } \\
\text { Item }\end{array}$} \\
\hline & $\begin{array}{c}\text { MVA } \\
\text { Patients } \\
\mathrm{N}=80 \\
\end{array}$ & $\begin{array}{c}\text { US } \\
\text { Veterans } \\
\mathrm{N}=468 \\
\end{array}$ \\
\hline $\begin{array}{l}\text { 1. Repeated, disturbing, and unwanted memories } \\
\text { of the stressful experience? }\end{array}$ & 9 & 4 \\
\hline $\begin{array}{l}\text { 2. Repeated, disturbing dreams of the stressful } \\
\text { experience? }\end{array}$ & 18 & 15.5 \\
\hline $\begin{array}{l}\text { 3. Suddenly feeling or acting as if the stressful } \\
\text { experience were actually happening again (as if } \\
\text { you were actually back there reliving it)? }\end{array}$ & 16.5 & 18 \\
\hline $\begin{array}{l}\text { 4. Feeling very upset when something reminded } \\
\text { you of the stressful experience? }\end{array}$ & 4 & 2 \\
\hline $\begin{array}{l}\text { 5. Having strong physical reactions when } \\
\text { something reminded you of the stressful } \\
\text { experience (for example, heart pounding, trouble } \\
\text { breathing, sweating)? }\end{array}$ & 6 & 10.5 \\
\hline $\begin{array}{l}\text { 6. Avoiding memories, thoughts, or feelings } \\
\text { related to the stressful experience? }\end{array}$ & 12.5 & 7.5 \\
\hline $\begin{array}{l}\text { 7. Avoiding external reminders of the stressful } \\
\text { experience (for example, people, places, } \\
\text { conversations, activities, objects, or situations)? }\end{array}$ & 12.5 & 7.5 \\
\hline $\begin{array}{l}\text { 8. Trouble remembering important parts of the } \\
\text { stressful experience? }\end{array}$ & 19 & 19 \\
\hline $\begin{array}{l}\text { 9. Having strong negative beliefs about yourself, } \\
\text { other people, or the world (for example, having } \\
\text { thoughts such as: I am bad, there is something } \\
\text { seriously wrong with me, no one can be trusted, } \\
\text { the world is completely dangerous)? }\end{array}$ & 16.5 & 15.5 \\
\hline $\begin{array}{l}\text { 10. Blaming yourself or someone else for the } \\
\text { stressful experience or what happened after it? }\end{array}$ & 12.5 & 13 \\
\hline $\begin{array}{l}\text { 11. Having strong negative feelings such as fear, } \\
\text { horror, anger, guilt, or shame? }\end{array}$ & 6 & 4 \\
\hline $\begin{array}{l}\text { 12. Loss of interest in activities that you used to } \\
\text { enjoy? }\end{array}$ & 2.5 & 10.5 \\
\hline 13. Feeling distant or cut off from other people? & 9 & 7.5 \\
\hline $\begin{array}{l}\text { 14. Trouble experiencing positive feelings (for } \\
\text { example, being unable to feel happiness or have } \\
\text { loving feelings for people close to you)? }\end{array}$ & 15 & 13 \\
\hline $\begin{array}{l}\text { 15. Irritable behavior, angry outbursts, or acting } \\
\text { aggressively? }\end{array}$ & 12.5 & 17 \\
\hline $\begin{array}{l}\text { 16. Taking too many risks or doing things that } \\
\text { could cause you harm? }\end{array}$ & 20 & 20 \\
\hline 17. Being super alert or watchful or on guard? & 2.5 & 4 \\
\hline 18. Feeling jumpy or easily startled? & 9 & 13 \\
\hline 19. Having difficulty concentrating? & 6 & 7.5 \\
\hline 20. Trouble falling or staying asleep? & 1 & 1 \\
\hline
\end{tabular}

It is noteworthy that the most salient symptom, i.e., the symptom endorsed most frequently, both by the post-MVA patients and by the US veterans was "trouble falling or staying asleep" (Item 20). 
The second most frequently endorsed item by the veterans was "feeling very upset" by reminders of "the stressful experience" (Item 4). For post-MVA patients, the second and third most frequently endorsed items were tied (mean rank 2.5): Item 17 ("being super alert or watchful or on guard") and Item 12 ("loss of interest" in previously enjoyable activities). It is of clinical interest that the least frequently endorsed PCL-5 items were identical in the sample of the post-MVA patients and veterans: Item 16 (taking risks) with the rank of 20 , and then, as the second least, the Item 8 ("trouble remembering important parts of the stressful experience") with the rank of 19.

\section{B. Extent of Overall Similarity of Relative Ranking of PCL-5 Items}

Spearman's coefficient calculated between the ranks given to PCL-5 items by the veterans and those by post-MVA patients indicated a high correlation ( $\mathrm{rho}=.83, \mathrm{p}<.001,2$ tailed). Some readers might prefer calculating the Pearson coefficient on the data because statistical studies by Havlicek and Peterson [10] indicated that that the Pearson $r$ is not markedly affected even by extreme violations of the basic theoretical assumptions such as the type of measurement scale. The Pearson correlation calculated on the same data was also high and at the same level ( $\mathrm{r}=.83, \mathrm{p}<.001,2$-tailed).

\section{Differences between Veterans and Post-MVA patients in the Rank Orders}

It is of clinical interest to determine on which items there were the largest differences between post-MVA patients and the veterans in their ranks. The difference of 8 ranks was noted with respect to Item 12 ("loss of interest" in previously enjoyed activities). The post-MVA patients reported the loss of interest with higher relative frequency (rank of 2.5) than the veterans (rank of 10.5). All other between groups differences were less than 6 ranks.

\section{DISCUSSION}

Veterans and the post-MVA patients showed a great similarity by endorsing with the highest relative frequency ( $1^{\text {st }}$ rank) the Item 20 ("trouble falling or staying asleep") and with the lowest frequency ( $20^{\text {th }}$ rank) Item 16 ("taking too many risks") and with the next lowest frequency (19 ${ }^{\text {th }}$ rank) the Item 8 "trouble remembering important parts of the stressful experience"). The penultimate rank for item 8 is consistent with trauma producing an accurate memory of the stressful experience. The intense memory of trauma, in conjunction with the top ranked item (insomnia), are typically the focus of therapy for veterans and post-MVA patients.

The impairment of sleep with a strong (and often intrusive) memory of a stressful experience are core components of a diagnosis of PTSD. The neurobiology of traumatic memories was reviewed by Diamond et al. [11] These investigators hypothesized that traumatic memories are composed of the powerful conjoint activation of the hippocampus and amygdala, formed in the absence of a moderating influence from the prefrontal cortex. This finding is consistent with the "warning signal hypothesis" of Ehlers et al. [12], in which there is intense and selective processing of cues e.g., sights, sounds and odors, present with onset of a stressful event.
As to the common finding of sleep difficulties in people with PTSD and in MVA patients, Diamond and Zoladz [13] speculated that the loss of sleep following trauma is the cost of inheriting an evolutionarily adaptive mechanism that considers hypervigilance, which enhances survival in a potentially threatening environment, more important than the quality of one's life.

The relative ranks on the PCL-5 items can be considered as providing a clinical profile of the patients. The overall similarity of these clinical profiles of the veterans and of postMVA patients, i.e., of their respective ranking the relative importance of PCL-5 items, is high, as shown by the Spearman's rho of 0.83 .

Salient between group differences were on Item 12 (loss of interest in previously enjoyed activities): post-MVA patients endorsed this item with higher relative frequency than veterans. Presumably, this sample of post-MVA patients were still in an early stage of recovery from persistent pain and from their post-concussive symptoms, i.e., at a stage in which engaging in previously enjoyed activities is less viable. As mentioned, their mean rating on the "average pain" item of the Brief Pain Inventory [5] (scale from $0=$ no pain to $10=$ pain as bad as you can imagine) was $6.2(\mathrm{SD}=1.7)$ and their average Rivermead [12], [13] post-concussion score was 45.5 $(\mathrm{SD}=8.5)$. All except one MVA patient reported pain, and $82.5 \%$ of the patients rated their pain as more than mild. All MVA patients experienced some postconcussive symptoms: the lowest Rivermead score in their sample was 28 .

Unfortunately, we did not have the veterans' ratings on the pain and post-concussion questionnaires.

Some statisticians may inquire about the Pearson correlation of the original mean item scores as reported in the PCL-5 study on MVA patients by Cernovsky et al. [4] and those in the study by Bovin et al. [3] The Pearson correlation of those two sets of mean values on the 20 PCL-5 items indicated a close relationship ( $\mathrm{r}=.88, \mathrm{p}<.001,2$-tailed $)$.

Some expert statisticians might recommend using z score transformation of the mean item scores, carried out separately for veterans and for MVA patients, to compare their item endorsement patterns on PCL-5. When we used the $\mathrm{z}$ score transformation in the present study, these were also highest in both groups on Item 20, indicating the particularly aversive nature of sleep difficulties both for the veterans and for MVA patients. The lowest $\mathrm{z}$ scores were on Item 16 and then on Item 8 , indicating that the symptom of taking too many risks and the symptom of having difficulties to recall some aspects of the stressful events were considered of lesser importance by both clinical groups. Thus, the results of the $\mathrm{z}$ score approach and of simple rank ordering have been very similar, in this particular study. The disadvantage of the procedure of $\mathrm{z}$ score transformation is that it tends to be more difficult for non-statisticians to comprehend than the approach involving simple rank ordering of the PCL-5 items.

A methodological problem involved both in the rank ordering approach and in the use of $\mathrm{z}$ scores lies in the possibility that the rank-order and also the $\mathrm{z}$ score pattern, i.e., the clinical profile on PCL-5, might considerably change when PCL-5 total scores markedly increase or decrease in their intensity. One method of examining this possibility would be dividing the patients within the same clinical group into those with milder PTSD (e.g., with scores from 34 to 55) 
to those with more severe PTSD (e.g., scores from 56 to 80) and compare PCL-5 profiles of these two groups as obtained via ranks or $\mathrm{z}$ scores.

Of clinical interest would be also an evaluation of how relative ranks of PCL-5 items of the same patients, i.e., their clinical PTSD profiles, may change with increasing time since the stressful event and hence hopefully with the progress of their recovery.

\section{REFERENCES}

[1] Weathers FW, Litz BT, Keane TM, Palmieri PA, Marx BP, \& Schnurr PP. The PTSD Checklist for DSM-5 (PCL-5). The National Center for PTSD, US Department of Veterans Affairs, Washington, DC, 2013. www.ptsd.va.gov.

[2] Blevins CA, Weathers FW, Davis MT, Witte TK, and Domino JL. The Posttraumatic Stress Disorder Checklist for DSM-5 (PCL-5): Development and Initial Psychometric Evaluation. Journal of Traumatic Stress. 2015;28:489-498. doi: 10.1002/jts.22059.

[3] Bovin MJ, Marx BP, Weathers FW, Gallagher MW, Rodriguez P, Schnurr PP, Keane TM. Psychometric properties of the PTSD checklist for diagnostic and statistical manual of mental disorders - fifth edition (PCL-5) in veterans. Psychological Assessment. 2016;28:1379-91.

[4] Cernovsky ZZ, Fattahi M, Litman LC, and Diamond DM. Validation of the PTSD Checklist for DSM-5 (PCL-5) on Patients Injured in Ca Accidents. European Journal of Medical and Health Sciences. 2021;3(2):154-159.

[5] Cleeland CS. The Brief Pain Inventory - User Guide. Houston, TX: The University of Texas - M. D. Anderson Cancer Center, 2009.

[6] Morin CM, Belleville G, Bélanger L, and Ivers H. The insomnia severity index: psychometric indicators to detect insomnia cases and evaluate treatment response. Sleep. 2011; 34:601-608.

[7] King NS, Crawford S, Wenden FJ, Moss NEG, Wade DT. The Rivermead Post Concussion Symptoms Questionnaire: a measure of symptoms commonly experienced after head injury and its reliability. Journal of Neurology. 1995;242:587-592.

[8] Cernovsky ZZ, Mann SC, Velamoor V, Oyewumi LK, Diamond DM, Litman LC. Validation of the Rivermead Post-Concussion Symptoms
Questionnaire (RPQ) on Patients Injured in High Impact Car Accidents. Archives of Psychiatry and Behavioral Sciences. 2021;4(1):14-22. doi.org/10.22259/2638-5201.0401003

[9] Cernovsky ZZ, Litman LC, Mann SC, Oyewumi LK, Bureau Y, Mendonça JD, Diamond DM, and Raheb H. Validation of the Subjective Neuropsychological Symptoms Scale (SNPSS) in Injured Motorists. Archives of Psychiatry and Behavioral Sciences. 2021;4(1):6-13.

[10] Havlicek LL, \& Peterson NL. Effect of the violation of assumptions upon significance levels of the Pearson r. Psychological Bulletin. 1977;84(2):373-377. doi.org/10.1037/0033-2909.84.2.373.

[11] Diamond DM, Campbell AM, Park, CR, Halonen, J, Zoladz, PR. The Temporal Dynamics Model of Emotional Memory Processing: A Synthesis on the Neurobiological Basis of Stress-Induced Amnesia, Flashbulb and Traumatic Memories, and the Yerkes-Dodson Law. Neural Plasticity. 2007; 60803: 1-33. doi:10.1155/2007/60803.

[12] Ehlers A, Hackmann A, Steil R, Clohessy S, Wenninger K, and Winter $\mathrm{H}$. The nature of intrusive memories after trauma: the warning signal hypothesis. Behaviour Research and Therapy. 2002;40(9):995-1002.

[13] Diamond DM and Zoladz PR. Dysfunctional or Hyperfunctional? The Amygdala in Posttraumatic Stress Disorder Is the Bull in the Evolutionary China Shop. Journal of Neuroscience Research. 2016;94:437-444 doi: 10.1002/jnr.23684

Zack Z. Cernovsky, is the professor of psychiatry in the medical schoo of Western University, London, Ontario, Canada. Dr. Cernovsky has published close to 200 scientific articles in the field of psychiatry and medical psychology, and also chapters in university textbooks.

Milad Fattahi, is completing master's degree requirements in psychology at Adler Graduate Professional School, Toronto, Ontario, Canada. He has co-authored various publications on psychological symptoms of injured motorists.

David M. Diamond, received his Ph.D. in Neuroscience from the University of California, Irvine. He is a professor in the Department of Psychology at the University of South Florida and recently retired from the Department of Veterans Affairs as a Career Scientist. Professor Diamond has published over 100 papers on the brain, stress, memory, and PTSD. 